\title{
Imagens de Educação Ambiental de futuros professores de Ciências Biológicas
}

\section{Environmental education images of future biologica sciences teachers}

\author{
Nathan da Matta Oliveira ${ }^{1}$ | nathan_matta_@hotmail.com \\ Melissa Reis ${ }^{1}$ \\ Raiele do Valle Perlingeiro ${ }^{1}$ \\ Ana Carolina Frazão ${ }^{1}$ \\ Karoline Claussen ${ }^{1}$ \\ Tatiana Galieta ${ }^{1}$
}

\section{RESUMO}

Estudos sobre concepções de Educação Ambiental (EA) de futuros professores têm sinalizado aspectos interessantes da formação inicial os quais poderão futuramente influenciar em suas práticas escolares. Neste trabalho relatamos parcialmente uma pesquisa realizada com alunos da licenciatura em Ciências Biológicas da Faculdade de Formação de Professores, Universidade do Estado do Rio de Janeiro. Aqui apresentamos os resultados relacionados especificamente às imagens de EA de uma amostra de licenciandos do referido curso. Os resultados preliminares apontam uma visão de EA centrada no conceito de conscientização e na resolução de problemas ambientais.

Palavras-chave: Educação Ambiental; formação de professores; ensino de ciências.

\section{ABSTRACT}

Studies on conceptions of Environmental Education of future teachers have shown interesting aspects of initial formation which may influence their future teaching practices. This paper reports preliminary results of a research conduct with students of an undergraduation course in Biological Sciences from a public university in Rio de Janeiro, Brazil. The results related specifically to the images of environmental education of a sample of these students are presented. The main conclusion points to a conception of environmental education focused on the concept of awareness and environmental problem solving.

Keywords: Environmental education, teacher formation, science teaching.

1 Universidade do Estado do Rio de Janeiro, Faculdade de Formação de Professores, São Gonçalo, RJ. 


\section{INTRODUÇÃO}

Atualmente, ainda são tímidas as iniciativas que inserem a Educação Ambiental (EA) em contextos educativos formais desde o estabelecimento da Política Nacional de Educação Ambiental (PNEA) em 2002². Percebemos que, apesar da EA ter entrada na escola via projetos de empresas privadas, de organizações não governamentais (ONGs) e de iniciativas isoladas dos professores, na maioria das escolas a EA é efetivada devido à iniciativa de organização e execução de projetos via mobilização de grupos de professores (TRAJBER e MENDONÇA, 2006).

Esse dado relevante acaba por levar-nos à necessidade de conhecer aspectos relacionados à formação inicial dos professores uma vez que eles se constituem nos principais formadores em temas relacionados à EA. Nesse sentido, alguns autores já vêm investigando as concepções de EA que professores de ciências atuantes nas escolas ou ainda em formação inicial possuem, entre eles: Del Nero e Frenedozo (2009), Souza e cols. (2011), Verona e Lorencini Jr. (2009).

Baseados na leitura dos trabalhos citados acima e motivados pelo estudo do histórico do campo da Educação Ambiental e de algumas práticas efetivadas em escolas que se deu no âmbito da disciplina Laboratório de Ensino I ${ }^{3}$ do curso de Ciências Biológicas, Faculdade de Formação de Professores (FFP) da Universidade do Estado do Rio de Janeiro (UERJ), os autores deste trabalho iniciaram um grupo de estudos no qual são discutidos aspectos relacionados à formação docente e sua futura atuação no magistério especificamente em temas ambientais. Surgiu, assim, o interesse pelo conhecimento de nossa própria realidade, do contexto no qual os licenciandos recém-ingressos no referido curso se deparariam ao longo de sua formação acadêmica.

\section{OBJETIVOS}

O objetivo geral do estudo consistiu em conhecer as imagens que licenciandos do curso de Ciências Biológicas da FFP/UERJ possuem em relação à Educação Ambiental. Tal estudo desdobrou-se nos seguintes objetivos específicos: (i) reconhecer as imagens de EA que os licenciandos apresentam; (ii) identificar as disciplinas do currículo do referido curso que os licenciandos consideram como sendo relevantes na formação em EA; (iii) perceber se os licenciandos respondentes do questionário se consideram prontos para ensinar temas de EA em suas futuras turmas escolares.

Frisamos que no presente trabalho apresentamos apenas os resultados referentes à primeira etapa dessa pesquisa a qual ainda pretende buscar nas ementas das disciplinas mencionadas pelos licenciandos marcas textuais que demarquem as diferentes visões de EA, bem como analisar discursos dos professores formadores e de um grupo de licenciandos de modo que aspectos relacionados às suas imagens de EA sejam esclarecidos.

\section{METODOLOGIA}

Nossas análises pautam-se em uma abordagem crítica de EA com a qual nos identificamos e acreditamos ser congruente com nossa filosofia educacional segundo a qual educar é um ato político que visa à transformação e libertação do educando de uma situação opressora (FREIRE, 1987). A vertente crítica de EA pretende superar a visão conservacionista que é característica das primeiras atividades de EA no Brasil (LOUREIRO, 2012). No

2 O Decreto no 4.281 de 25/06/2002 regulamentou a Lei no 9.795, de 27/04/1999, estabelecendo a PNEA que, entre outros pontos, qualificava a educação ambiental como componente essencial e permanente da educação nacional, tendo como âmbitos de ação a educação formal e não formal.

3 A disciplina Laboratório de Ensino I é ministrada no $1^{\circ}$ período da licenciatura em Ciências Biológicas, da FFP/UERJ, e possui, entre outros, os seguintes objetivos: compreender as questões de saúde, ambiente e sexualidade a partir de uma perspectiva histórica e analisar práticas e materiais didáticos envolvendo os temas educação ambiental, saúde e sexualidade no contexto da escola básica e de espaços educativos não-formais. 
entanto, não podemos deixar de reconhecer que, ainda hoje, encontramos vertentes de EA que vão desde aquela visão pautada na ideia de transmissão de conhecimentos para o "doutrinamento" de comportamentos, passando por tendências intermediárias, até uma visão crítica e transformadora. Acreditamos que isso esteja relacionado à própria constituição do campo da EA ainda recente no Brasil (cerca de apenas 30 anos). Sem dúvidas, que essa tendência pode ser encontrada nos discursos de educadores de diferentes níveis e de futuros professores.

Para identificarmos as imagens que os licenciandos do curso de Ciências Biológicas da FFP/UERJ possuem com relação à EA, fizemos um questionário com sete questões fechadas (6) e abertas (2) . Tanto para a elaboração do questionário como para a análise dos resultados baseamo-nos nas categorias propostas por Cunha e cols. (2006) e Silva e Campina (2009). Apesar dos resultados quantitativos serem apresentados, sobretudo na forma de gráficos, entendemos que a pesquisa também possui um caráter qualitativo na análise dos dados.

O questionário foi respondido pelo total de 104 licenciandos, distribuídos entre o $2^{\circ}$ e $7^{\circ}$ período (com exceção do $3^{\circ}$ período $)^{5}$. Os dados foram coletados durantes aulas de disciplinas obrigatórias com a devida permissão dos professores responsáveis. Os alunos recebiam, então, os questionários sem qualquer tipo de orientação e apenas eram informados sobre sua finalidade. Alguns deles não responderam ao questionário ou responderam de forma incorreta algumas questões. Nesses casos, tais questionários ou respostas foram desconsiderados.

\section{RESULTADOS E DISCUSSÃO}

A seguir apresentamos os resultados obtidos para cada uma das três primeiras questões as quais se referiam às visões de ambiente e concepções de EA dos licenciandos.

\section{1) Termo mais adequado para definir "Educação Ambiental”}

A primeira questão foi apresentada da seguinte forma:

1. Ao pensar em "Educação Ambiental" que termo lhe parece mais adequado para defini-la? (Marque apenas uma opção!)

( ) preservação

( ) conscientização

( ) mudança de atitudes

( ) questões sócio-econômicas

( ) conservação

( ) sustentabilidade

Por ser ainda um campo recente e em constituição, a EA tem sido concebida por seus pesquisadores a partir de concepções diversificadas de ambiente, estabelecendo em maior ou menor grau diálogos com outras áreas do conhecimento. Desta forma, a própria concepção de EA pode ser compreendida deste uma visão mais

4 No presente trabalho apresentamos os resultados referentes às três primeiras questões. As demais não serão apresentadas e analisadas pela restrição da extensão do mesmo.

5 No semestre anterior à coleta de dados, pelo levantamento realizado pela secretaria do Departamento de Ciências, 277 alunos estavam regularmente matriculados no curso. Assim, considerando este universo populacional temos uma amostra de 37,5\% a qual pode ser estimada como sendo representativa da população. 
restrita - ainda vinculada à ideia conservacionista e preservacionista - até uma concepção mais crítica que busca considerar aspectos sociais e políticos. Ao observarmos o Gráfico 1 percebemos que o termo mais utilizado para definir a EA de acordo com os licenciandos é “conscientização” (64\%).

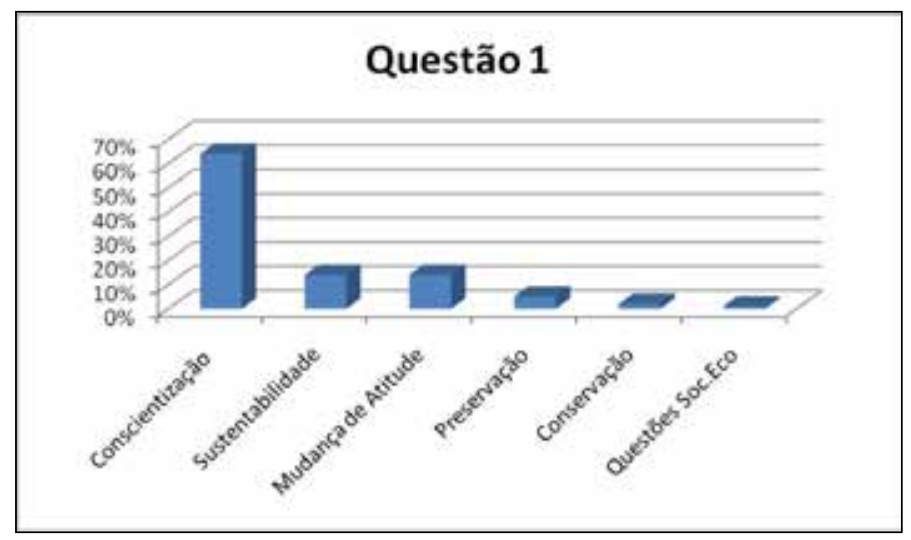

Gráfico 1: percentual de respostas obtidas na questão 1.

É interessante notar que o conceito de conscientização nasce nas obras de Paulo Freire e é apropriado por vertentes críticas de EA. Aqui, considera-se que o processo de tomada de consciência pelo sujeito apenas assume uma perspectiva de conscientização crítica (e não ingênua) quando o mesmo é capaz de (re)conhecer a causalidade dos fenômenos sociais e da historicidade de suas ações possibilitando-o construir sua autonomia (FREIRE, 1979). Apesar de encontrarmos um valor expressivo desta resposta, não podemos afirmar que os licenciandos que assinalaram esta opção de fato possuem o conceito de conscientização conforme descrito acima, daí a importância das futuras entrevistas. Vale ainda ressaltar que as demais opções tiveram resultados equilibrados: sustentabilidade e mudança de atitude (14\% cada), algo que relacionamos ao discurso tradicional da EA. Além disso, foram ainda obtidos $5 \%$ das respostas para preservação e apenas $1 \%$ para questões sócio-econômicas.

\section{2) Visões de Educação Ambiental}

Nesta questão, apoiamo-nos nas categorias estabelecidas por Cunha e cols. (2006) para tentarmos nos aproximar das concepções de EA dos licenciandos. Foram apresentadas frases que representavam quatro tipos de concepções as quais foram ordenadas (aleatoriamente) no questionário da seguinte forma: A) Integradora; B) Transformação Social; C) Tradicional; D) Resolução de Problemas, conforme o texto a seguir:

2. Assinale com um $X$ o item abaixo que você considera como sendo aquele que melhor representa sua visão de Educação Ambiental (EA):

( ) "A questão ambiental abrange toda a complexidade da ação humana, desse modo para não atribuir à EA um caráter reducionista, é necessário que se aborde temas que vão desde questões sociais até a conservação do meio ambiente.”

( ) "O que realmente importa dentro de um programa de EA é que as comunidades se organizem e façam dessa organização a sua força de luta na busca de condições dignas de vida. Essa ação deve significar uma auto-reflexão promovida junto à comunidade, que leve à aquisição de uma consciência crítica de sua realidade.”

( ) “A questão ecológica ou ambiental deve-se restringir à preservação dos ambientes naturais e o combate à poluição. É preciso, portanto, estabelecer o campo do saber ambiental, e relacioná-lo diretamente com EA. Caso contrário, ao querer transformar tudo em EA, estaríamos submetendo-a a banalização.” 
( ) “A EA deve enfatizar a ação, deve estar vinculada a atividades práticas, voltadas para problemas concretos, como coleta seletiva de lixo, plantio de árvores, entre outros. Sendo assim, a EA vista como necessária na busca de soluções para os problemas ambientais, acaba por despertar no cidadão a necessidade do compromisso com a natureza, no sentido de utilizá-la de forma racional.”

As respostas obtidas são apresentadas no Gráfico 2.

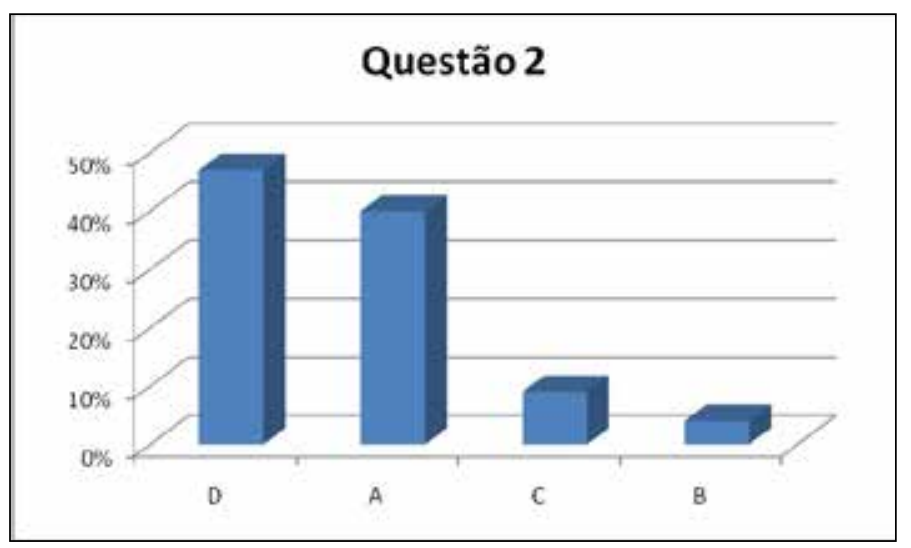

Gráfico 2: percentual de respostas obtidas na questão 2.

Pudemos observar um equilíbrio entre as concepções denominadas "resolução de problemas” (47\%) e "integradora” (40\%). Estes resultados estão em sintonia com aqueles encontrados por Verona e Lorencini Jr. (2009) em sua pesquisa com licenciandos da Universidade Estadual de Londrina. De acordo com Cunha e cols. (2006), pessoas que apresentam a concepção "resolução de problemas" associam a EA à "utilização racional do meio ambiente levando em conta aspectos de desenvolvimento sustentável e gestão ambiental" (CUNHA et al., 2006, p. 30). Enquanto que os filiados à concepção "integradora" possuem um "entendimento mais global da questão ambiental" uma vez que concebem "relações dinâmicas entre aspectos naturais, sociais e culturais" (idem). É interessante notar que ao apresentarmos frases que poderiam definir sua concepção de EA, quase metade dos licenciandos optou por uma visão que se encontra em sintonia com o discurso de desenvolvimento sustentável tão presente na mídia e que, de certa forma, se opõe aos $14 \%$ obtidos na primeira questão para a opção "sustentabilidade”. A segunda colocação para a concepção "integradora” permite-nos inferir que os licenciandos não associam a EA apenas à conservação considerando também o meio sócio-cultural que constitui (e é constituído) o (pelo) ambiente. As concepções "tradicional” e "transformação social” apresentaram 9\% e $4 \%$ das respostas, respectivamente. A primeira está vinculada a uma visão antropocêntrica segundo a qual o homem assume uma relação utilitarista e preservacionista com a natureza. Já a segunda, apresenta um enfoque sócio-político-ambiental com uma “desterritorialização da EA”.

\section{3) Situações problemáticas do ponto de vista ambiental}

A terceira questão foi formulada da seguinte forma:

3. Abaixo são apresentadas situações que podem ser consideradas problemáticas do ponto de vista ambiental. Numere, em ordem decrescente de importância, cada um desses fatores. (Atribuindo 1 para o mais importante e 6 para o menos importante.)

( ) poluição

( ) atuação do homem na natureza

( ) questões sociais e econômicas 


\section{( ) desmatamento}

( ) falta de consciência ambiental

( ) escassez dos recursos naturais

Para classificarmos os resultados obtidos nessa questão foi contabilizado o total de votos nas seis opções em cada uma das posições (de 1 a 6). Assim, obtivemos a colocação predominante dentro de cada uma das opções. Por exemplo, a opção “falta de consciência ambiental” obteve o maior número de votos (39, do total de 103) na primeira colocação ficando, desta forma, no primeiro lugar geral. A seguir apresentamos na Tabela 1 os resultados gerais para esta questão.

Tabela 1: respostas à questão 3

\begin{tabular}{c|c}
\hline Ordem de importância & Situações problemáticas \\
\hline $1^{\circ}$ & Falta de consciência ambiental \\
\hline $2^{\circ}$ & Atuação do homem na natureza \\
\hline $3^{\circ}$ & Desmatamento \\
\hline $4^{\circ}$ & Poluição \\
\hline $5^{\circ}$ & Escassez dos recursos naturais \\
\hline $6^{\circ}$ & Questões sociais e econômicas \\
\hline
\end{tabular}

Pelas respostas obtidas nesta questão podemos notar que os licenciandos - contradizendo em parte os resultados da $2^{\mathrm{a}}$ questão - identificam como questões ambientais problemáticas situações que estão intimamente ligadas ao ser humano pois tanto a ausência de consciência ambiental quanto a interferência do homem na natureza sinalizam uma aproximação à visão antropocêntrica intrínseca a uma concepção tradicional de EA.

De certa forma, poderíamos compreender que as demais opções (desmatamento, poluição e escassez de recursos naturais) também estão relacionadas ao estilo de vida humana, sobretudo, em sociedades capitalistas, basicamente urbanas e industriais. Estas opções se remetem em última instância a questões sociais e econômicas as quais, segundo o nosso entendimento em sintonia com a EA crítica, situam-se na base das decisões políticas que afetam o modo de exploração dos recursos naturais e de consumo individual. Assim, entendemos que os resultados da terceira questão sinalizam a necessidade de contemplar nas disciplinas do currículo do curso de formação inicial discussões mais amplas que promovam o diálogo entre ambiente e aspectos de organização da sociedade.

\section{CONCLUSÕES}

O presente trabalho apresentou uma análise inicial das respostas de licenciandos do curso de Ciências Biológicas da FFP/UERJ a um questionário que visou reconhecer suas imagens de Educação Ambiental. Ao serem questionados sobre o termo mais adequado para definir EA, a maioria dos licenciandos escolheu a palavra “conscientização”. Acreditamos que este resultado tanto pode sinalizar uma concepção crítica de EA segundo a qual a conscientização está relacionada a uma postura de transformação da realidade do entorno social do sujeito quanto a uma concepção conservacionista que pretende a simples mudança de comportamentos.

Com relação às visões de EA, aproximadamente metade dos futuros professores escolheu a frase relacionada à concepção de “resolução de problemas”, sendo a visão “integradora” a segunda colocada. De uma forma geral, este resultado pode nos indicar um avanço no que diz respeito às concepções ambientalistas conservacio- 
nistas tradicionais. No entanto, obtivemos um resultado aparentemente contraditório a este na terceira questão. Nela, as duas situações consideradas como sendo mais problemáticas do ponto de vista ambiental estão relacionadas a uma visão antropocêntrica (a falta de consciência ambiental e a atuação do homem na natureza), embora todas as demais alternativas estejam relacionadas de alguma forma aos impactos causados pela exploração dos recursos naturais pelo homem. Por outro lado, os resultados da terceira questão reforçam a importância do conceito de "conscientização/consciência ambiental”. Desta forma, consideramos fundamental a segunda etapa da pesquisa que consistirá em entrevistas com alguns dos licenciandos respondentes ao questionário.

\section{REFERÊNCIAS BIBLIOGRÁFICAS}

CAVALCANTI NETO, A. L. G. e AMARAL, E. M. R. do. Análise de concepções e visões de professores de ciências sobre educação ambiental. Pesquisa em Educação Ambiental, vol. 6, n. 2, p. 119-136, 2011.

CUNHA, A. M. de O.; CHIRIELEISON, E. e GUIDO, L. de F. E. Conhecendo a própria concepção de Educação Ambiental. In: Caderno de Programas e Resumos do X Encontro Perspectivas do Ensino de Biologia. Campinas, SP: FE/UNICAMP, 2006.

DEL NERO, F. G. e FRENEDOZO, R. de C. Concepções dos discentes dos cursos de licenciatura sobre educação ambiental, sua responsabilidade social e o papel formativo da universidade. In: Atas do VII Encontro Nacional de Pesquisa em Educação em Ciências. Florianópolis: ABRAPEC, 2009.

FREIRE, P. Pedagogia do Oprimido. 17. ed. Rio de Janeiro: Paz e Terra, 1987.

Conscientização: teoria e prática da libertação: uma introdução ao pensamento de Paulo Freire. Tradução de Kátia de Mello e Silva. São Paulo: Cortez \& Moraes, 1979.

LOUREIRO, C. F. B. Sustentabilidade e educação: um olhar da ecologia política. São Paulo: Cortez, 2012.

SILVA, R. L. F. e CAMPINA, N. N. Tipologia de análise de concepções de educação ambiental: possibilidades e limites para o reconhecimento da pluralidade da área. In: Anais do V Encontro de Pesquisa em Educação Ambiental. São Carlos, SP: UFSCar, 2009.

SOUZA, V. M. de.; KELECOM, A. e ARAUJO, Joel de. A educação ambiental: conceitos e abordagens pelos alunos de licenciatura da Universidade Federal Fluminense. Revista Uniara, vol.14, n.1, 2011.

TRAJBER, R. e MENDONÇA, P. R. (Orgs.). Educação na diversidade: o que fazem as escolas que dizem que fazem educação ambiental. Brasília: Secretaria de Educação Continuada, Alfabetização e Diversidade, 2006.

VERONA, M. F. e LORENCINI JR, A. Concepções de Educação Ambiental e a Formação Inicial de Professores de Ciências e Biologia: uma análise da Universidade Estadual de Londrina (UEL/PR). In: Anais do V Encontro de Pesquisa em Educação Ambiental. São Carlos, SP: UFSCar, 2009. 